\title{
Urban Trends and Economic Development in China: Geography Matters!
}

\author{
Michel Dimou, Alexandra Schaffar \\ LEAD-University of Toulon, Toulon, France \\ Email: dimou@univ-tIn.fr, schaffar@univ-tIn.fr
}

Received 5 June 2014; revised 15 July 2014; accepted 10 August 2014

Copyright (C) 2014 by authors and Scientific Research Publishing Inc.

This work is licensed under the Creative Commons Attribution International License (CC BY). http://creativecommons.org/licenses/by/4.0/

c) (i) Open Access

\begin{abstract}
The aim of this paper is to document the role of spatial effects in the relationship between urban trends and economic development in China, between 1984 and 2004. During this period the Chinese urban system experienced dramatic changes, with significant rural-urban, intra-provincial and interprovincial migration, mainly after the 1993 reforms that eased the former Hukou rule and abolished the prevailing cross-region labor mobility restrictions. This study draws upon recent econometrical tools based on spatial panel data models, developed in order to deliver evidence for a linear relationship between urbanization rates and GDP per capita and an inverted-U relationship between urban primacy and GDP per capita in the Chinese provinces.
\end{abstract}

\section{Keywords}

Urbanization, Urban Primacy, Inverted-U Theories, China

\section{Introduction}

Following work from Williamson (1965), Rosen and Resnick (1980) argue that developing regions feature transitional urban dynamics: urban concentration characterises the first stages of economic development under agglomeration scale economies and rural-urban migration; demographical dispersion appears within more developed countries, because of the geographical diffusion of market effects and lower transport costs due to mass transport technologies. Wheaton and Shishido (1981) assume an inverted-U curve relationship between urbanisation and the non-agriculture gross domestic product. According to MacKellar and Vining (1995), most countries feature a 5000\$ per capita income trade-off point, above which urbanisation trends change. Junius (1999) explored the hypothesis of an inverted $\mathrm{U}$ curve between economic development and urban primacy. Catin et al. (2008) examine a three stages' development model with regards to urbanisation dynamics: the first stage features a pre-industrial economy, with low GDP/capita and weak urbanisation; the second stage corresponds to 
industrial take-off, economic polarisation and urban concentration; finally during the third stage, high-tech production leads to diffuse demographical growth.

Using 1950-2050 data, the UN World Urban Prospects (2009) indicate an apparent relationship between the level of economic development and the percentage of urban population. However, this relationship is complex: wealthy regions may have lower urbanization levels, while less developed regions may be associated with higher urbanization rates. Moomaw and Alwosabi (2004) argue that when per capita income level is lower than $1600 \$$, the relationship between the two aggregates is rather loose. It becomes significant above this threshold but below 25,000\$. Ades and Gleser (1995) introduce institutional factors to explain urbanization patterns, with public transport equipment being among the most important variables. In their comparative study of 85 countries, Davis and Henderson (2003) deliver evidence for the role of a country's political regime on urban primacy.

These studies deliver additional information on the relationship between economic development and urbanization but forget its geographical dimension. Wealthy regions or countries with high urbanization rates are often neighbors. Similarly, neighboring poor countries feature same urbanization patterns, with lower urban population but higher primacy rates. The aim of this paper is to document spatial auto-correlation in the relationship between urban trends and the GDP/capita level in the Chinese provinces, between 1984 and 2004. During this period, China experienced dramatic changes, with significant rural-urban, intra-provincial and interprovincial migration, mainly after the 1993 reforms that eased the former Hukou rule and abolished the prevailing crossregion labor mobility restrictions. This study draws upon recent econometrical tools on spatial panel data models (Debarsy \& Ertur, 2010).

Section 2 focuses on methodological issues. Section 3 delivers the results for the a-spatial models applied on China's provinces' economic development and urbanization trends. Section 4 introduces spatial effects. The last section concludes.

\section{Methodology}

Following Catin et al. (2008), we use 2 equations: the first one determines each province's urbanization rate (URB), the second one its primacy rate (PRIM), defined as the part of the largest city among all the province's cities.

Three sets of explanatory variables are used: the first ones determine the level of economic development; the second ones measure the trade openness ratio, reflecting each province's access to international markets; the third ones concern intra-provinces transport conditions.

Gross Domestic Product (GDPC) per capita features the level of economic development. In order to test the existence of a non-linear relationship between urbanization and the GDP/capita, we also consider a quadratic term for the latter. Changes in GDP/capita may be due to productive accumulation or to global productivity gains without taking into account cross-industry effects in capital accumulation and employment. Non-agricultural employment (NAGRI) captures rural-urban migration related to productive accumulation and agricultureindustry transition.

A second set of variables concerns trade openness. The export rate (EXP) captures the ability of the Chinese provinces to interact with international markets. A third set of variables concerns transport equipment within each province. Following Krugman and Livas (1996), we use the railway network density, (TRD) that is the length of the provincial railway network compared to the province's land area.

Spatial auto-correlation is tested to detect cross-sectional dependence in urbanization and urban primacy related to distance. A battery of tests allows us to discriminate the different spatial models: the spatial autoregressive model (SAR) captures possible spatial interaction among the Chinese provinces' urban trends, the spatial error model (SEM) with a spatial autoregressive parameter of the error term and finally the SARAR model which contains both types of spatial auto-correlation. We present the most robust results, delivered with two different matrices: an inverse distance matrix with $d_{i j}$ the distance between the capitals of two provinces $i$ and $j$; a contiguity matrix, where two provinces with a common frontier are considered as neighbors.

Data is provided by China's Annual Statistical Yearbooks. The urban population is considered across the 2000 definition.

\section{Results}

China’s urban population increased from $15.1 \%$ of the total population in 1960 up to $23.4 \%$ in 1984 and $42.6 \%$ 
in 2004. The annual growth rate of GDP per capita was of 8.5\% during the 1978-1984 period, $10.2 \%$ from 1984 to 1994 and 6.6\% from 1994 to 2004. The following Figure 1 delivers information on the correlation between urbanization rate and GDP per capita level. The correlation is much stronger in 2004 than in 1984.

Table 1 and Table 2 deliver results for both equations (respectively, the dependent variables are the urbanization rate and the primacy rate) over the whole period, then for each sub-period (1984-1993 and 1994-2004).

Firstly, GDP/capita growth positively impacts urbanization and primacy rates; however there is not a peakeffect, as supposed by Rosen and Resnick. Our findings don't reveal any inverted-U relationship. The nonagricultural employment is well correlated with urbanization, but much less with urban primacy. Secondly, the railway density is not significant for urbanization. This can be explained by the fact that, once rural workers decide to move to the city, transport conditions don't seem important. TRD is a more accurate variable, when studying urban primacy, since inter-city mobility may affect an urban worker's locational choices. Thirdly, regarding model 1, the export rate becomes significant for urbanization after the 1993 reforms and China's opening to foreign investments. All the explanatory variables feature stronger impact on urbanization and urban primacy after 1993.

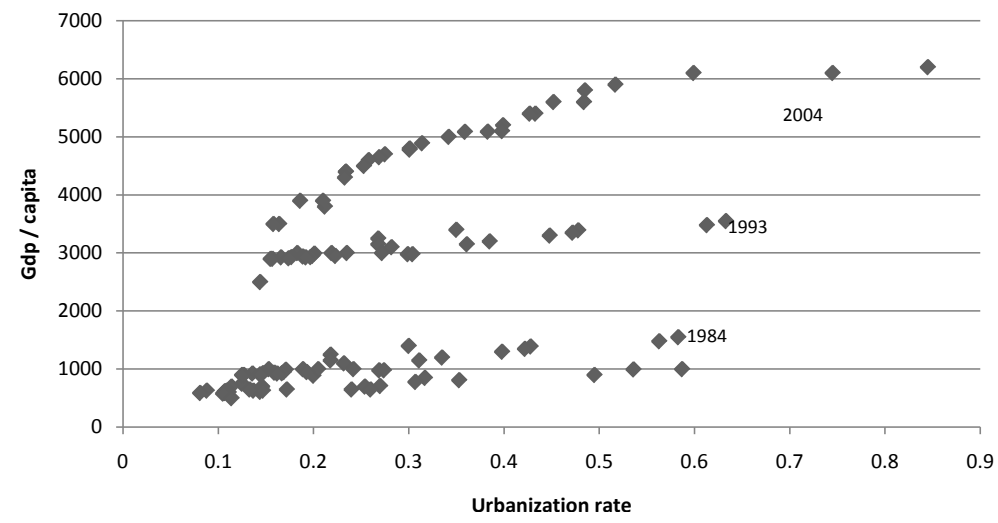

Figure 1. Urbanization rate and GDP/capita in China. Database: CSO (2004).

Table 1. Urbanization vs GDP/capita.

\begin{tabular}{cccc}
\hline & $1984-2004$ & $1984-1993$ & $1994-2004$ \\
\hline URB & & & \\
GDP & $0.613^{* * *}$ & $0.408^{* *}$ & $0.785^{* *}$ \\
GDP2 & $0.033^{* *}$ & $0.011^{*}$ & $0.041^{*}$ \\
NAGRI & $0.643^{* *}$ & $0.545^{* *}$ & $0.712^{* *}$ \\
EXP & $0.156^{* *}$ & $0.118^{* *}$ & $0.216^{* *}$ \\
TRD & $0.083^{* *}$ & $0.086^{*}$ & $0.077^{* *}$ \\
\hline
\end{tabular}

Table 2. Urban primacy vs GDP/capita.

\begin{tabular}{cccc}
\hline & $1984-2004$ & $1984-1993$ & $1994-2004$ \\
\hline PRIM & & & \\
GDP & $0.531^{* *}$ & $0.411^{* * *}$ & $0.671^{* *}$ \\
GDP2 & $0.008^{*}$ & n.s & n.s \\
NAGRI & $0.411^{* *}$ & $0.492^{* * *}$ & $0.390^{* *}$ \\
EXP & $0.089^{*}$ & $0.078^{*}$ & $0.196^{*}$ \\
TRD & $0.154^{*}$ & $0.151^{*}$ & $-0.177^{*}$ \\
\hline
\end{tabular}




\section{Introducing Spatial Dependence}

Next, we introduce spatial auto-correlation tests. Conditional hypothesis statistics $L M_{\lambda / \rho}$ and $L M_{\rho / \lambda}$ allow distinction between the alternative specifications for spatial auto-correlation. For the first equation, when the contiguity matrix is used, the null is rejected with both tests for the whole period as well as for each sub-period, which means that the best specification is the SARAR model. When using the inverse distance, the equation for urbanization in the Chinese provinces is best described by a SEM model. For the second equation, when using the inverse distance matrix, the most adequate model is the SARAR; when using the contiguity matrix, the best model is the SAR, which means that when an endogenous spatial lag is included, no residual spatial autocorrelation remains.

Table 3 delivers estimations for the spatial autoregressive parameters $\lambda$ and $\rho$ and for the regression parameters, through the maximum likelihood method.

There is a clear relationship between urbanization and provincial GDP/capita; nevertheless, this relationship doesn't reveal any inverted-U patterns. Neighboring effects seem stronger after the 1993 reforms. In the SEM model, spatial interdependence relies on spatial diffusion: an exogenous shock (for example the creation of an export process zone) leading to changes in a province's urbanization affects the neighboring provinces' urbanization rates but the impact of the shock decreases with distance.

Table 4 summarizes the results when running the urban primacy regression.

Table 3. Spatial model 1 parameters.

\begin{tabular}{ccccccc}
\hline & \multicolumn{3}{c}{ Inverse distance matrix } & \multicolumn{3}{c}{ Contiguity matrix } \\
& $1984-2004$ & $1984-1993$ & $1994-2004$ & $1984-2004$ & $1984-1993$ & $1994-2004$ \\
\hline GDP & SEM & SEM & SEM & SARAR & SARAR & SARAR \\
GDP2 & $0.557^{* *}$ & $0.399^{* *}$ & $0.641^{* *}$ & $0.321^{* *}$ & $0.297^{* *}$ & $0.426^{* *}$ \\
NAGRI & $0.021^{* *}$ & n.s. & $0.039^{*}$ & n.s. & n.s. & n.s. \\
EXP & $0.531^{* *}$ & $0.502^{* *}$ & $0.678^{* *}$ & $0.403^{* *}$ & $0.294^{* *}$ & $0.510^{* *}$ \\
TRD & $0.218^{* *}$ & $0.187^{*}$ & $0.233^{*}$ & $0.123^{*}$ & n.s. & $0.201^{*}$ \\
$\rho$ & $0.077^{*}$ & n.s. & $0.091^{*}$ & $0.065^{*}$ & n.s. & $0.79^{*}$ \\
& & & & 0.060 & 0035 & 0.073 \\
$\lambda$ & & & & $(4.235)$ & $(5.345)$ & $(6.698)$ \\
& 0.634 & 0.579 & 0.717 & 0.279 & 0.268 & 0.405 \\
\hline
\end{tabular}

Table 4. Spatial model 2 parameters.

\begin{tabular}{|c|c|c|c|c|c|c|}
\hline & \multicolumn{3}{|c|}{ Inverse distance matrix } & \multicolumn{3}{|c|}{ Contiguity matrix } \\
\hline & 1984-2004 & 1984-1993 & 1994-2004 & 1984-2004 & 1984-1993 & 1994-2004 \\
\hline & SARAR & SARAR & SARAR & SAR & SAR & SAR \\
\hline GDP & $0.311^{* *}$ & $0.303^{* *}$ & $0.392^{* *}$ & $0.321^{* *}$ & $0.297^{* *}$ & $0.426^{* *}$ \\
\hline $\mathrm{GDP}^{2}$ & $-0.103^{*}$ & n.s. & $-0.181^{*}$ & $-0.122^{*}$ & $0.097^{*}$ & $-0.121^{*}$ \\
\hline NAGRI & $0.412^{* *}$ & $0.401^{* *}$ & $0.711^{* *}$ & $0.612^{* *}$ & $0.334^{* *}$ & $0.699^{* *}$ \\
\hline EXP & $0.106^{*}$ & $0.092^{*}$ & $0.201^{*}$ & $0.113^{*}$ & $0.198^{*}$ & $0.255^{*}$ \\
\hline TRD & $0.177^{*}$ & $0.143^{*}$ & $-0.211^{*}$ & $0.151^{*}$ & n.s. & $-0.123^{*}$ \\
\hline \multirow[t]{2}{*}{$\rho$} & 0.224 & 0.143 & 0.345 & 0.751 & 0.677 & 0832 \\
\hline & $(1.013)$ & $(2.132)$ & $(5.123)$ & $(14.352)$ & (20.019) & $(26.975)$ \\
\hline \multirow[t]{2}{*}{$\lambda$} & 0.545 & 0.487 & 0.702 & & & \\
\hline & (4.209) & (1.317) & (1.854) & & & \\
\hline
\end{tabular}


There is a convex relationship between the Chinese provinces' urban primacy rates and the levels of GDP/ capita. The conclusions from the a-spatial model change, mainly after 1993, when the convexity of the relationship clearly strengthens: urban primacy follows an ascending trend until a certain level of economic development, then decreases. TRD is negatively correlated with urban primacy after 1993. Better transport conditions are necessary for demographical dispersion, once a certain threshold of economic development being achieved.

The SAR model implies a global spatial multiplier effect in addition to a spatial diffusion effect of random shocks. Changes in a province’s urban primacy rates multiply the changes occurring in neighboring provinces.

\section{Conclusions}

The paper examines the determinants of urban trends in China, by introducing spatial dependence effects. Three conclusions may be drawn:

Urbanization is positively correlated with GDP/capita. The introduction of spatial auto-correlation improves the model's prediction but doesn't fundamentally modify its conclusions: there are no inverted-U patterns.

Urban primacy is positively correlated with GDP/capita but the conclusions change when we introduce spatial effects: the relationship becomes convex. Urban primacy increases with rural-urban migration when GDP/capita grows until a certain threshold of economic development; once this threshold achieved, urban primacy decreases.

Provincial transport equipment is only relevant for urban primacy, when introducing spatial effects. When rural households move to town, transport issues are not important; however, they become significant when it comes to inter-city migration.

\section{References}

Ades, A., \& Glaeser, E. (1995). Trade and Circuses, Quarterly Journal of Economics, 110, 195-227. http://dx.doi.org/10.2307/2118515

Catin, M., Hanchane, S., \& Kamal, A. (2008). Urbanisation, primate et étapes de développement. Région et Développement, 27, 84-108.

Chinese Statistical Office (CSO) (2004). Chinese Urban Statistical Yearbooks.

Davis, J., \& Henderson, V. (2003). Evidence of the Political Economy of the Urbanisation Process. Journal of Urban Economics, 53, 98-123. http://dx.doi.org/10.1016/S0094-1190(02)00504-1

Debarsy, N., \& Ertur, C. (2010). Testing for Spatial Autocorrelation in a Fixed Effects panel Data Model. Regional Science and Urban Economics, 40, 453-470. http://dx.doi.org/10.1016/j.regsciurbeco.2010.06.001

Junius, K. (1999) Primacy and Economic Development: Bell Shaped or Parallel Growth of Cities? Journal of Economic Development, 24, 1-22.

Krugman, P., \& Livas, R. (1996). Trade Policy and the Third World Metropolis. Journal of Development Economics, 49, 137-150. http://dx.doi.org/10.1016/0304-3878(95)00055-0

MacKellar, F., \& Vining, D. (1995). Population Concentration in Less Developed Countries. Papers in Regional Science, 74, 3-30.

Moomaw, R., \& Alwosabi, M. (2004). An Empirical Analysis of Competing Explanations of Urban Primacy. Annals of Regional Science, 38, 149-171. http://dx.doi.org/10.1007/s00168-003-0137-x

Rosen, K., \& Resnick, M. (1980). The Size Distribution of Cities, Journal of Urban Economics, 8, 165-186. http://dx.doi.org/10.1016/0094-1190(80)90043-1

United Nations (2009) World Urban Prospects. United Nations, New York.

Wheaton, W., \& Shishido, H. (1981). Urban Concentration, Agglomeration Economies and Economic Development. Economic Development and Cultural Change, 30, 17-30.

Williamson, A. (1965). Regional Inequality and the Process of National Development. Economic Development and Cultural Change, 4, 3-47. 
Scientific Research Publishing (SCIRP) is one of the largest Open Access journal publishers. It is currently publishing more than 200 open access, online, peer-reviewed journals covering a wide range of academic disciplines. SCIRP serves the worldwide academic communities and contributes to the progress and application of science with its publication.

Other selected journals from SCIRP are listed as below. Submit your manuscript to us via either submit@scirp.org or Online Submission Portal.
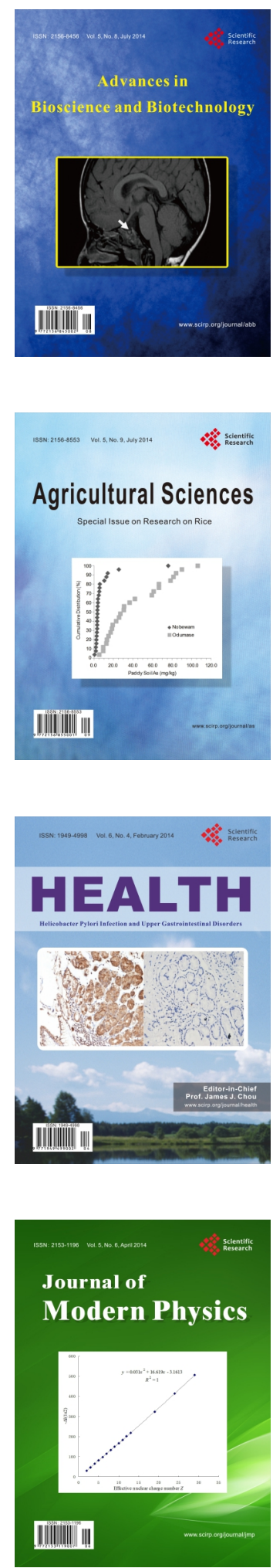
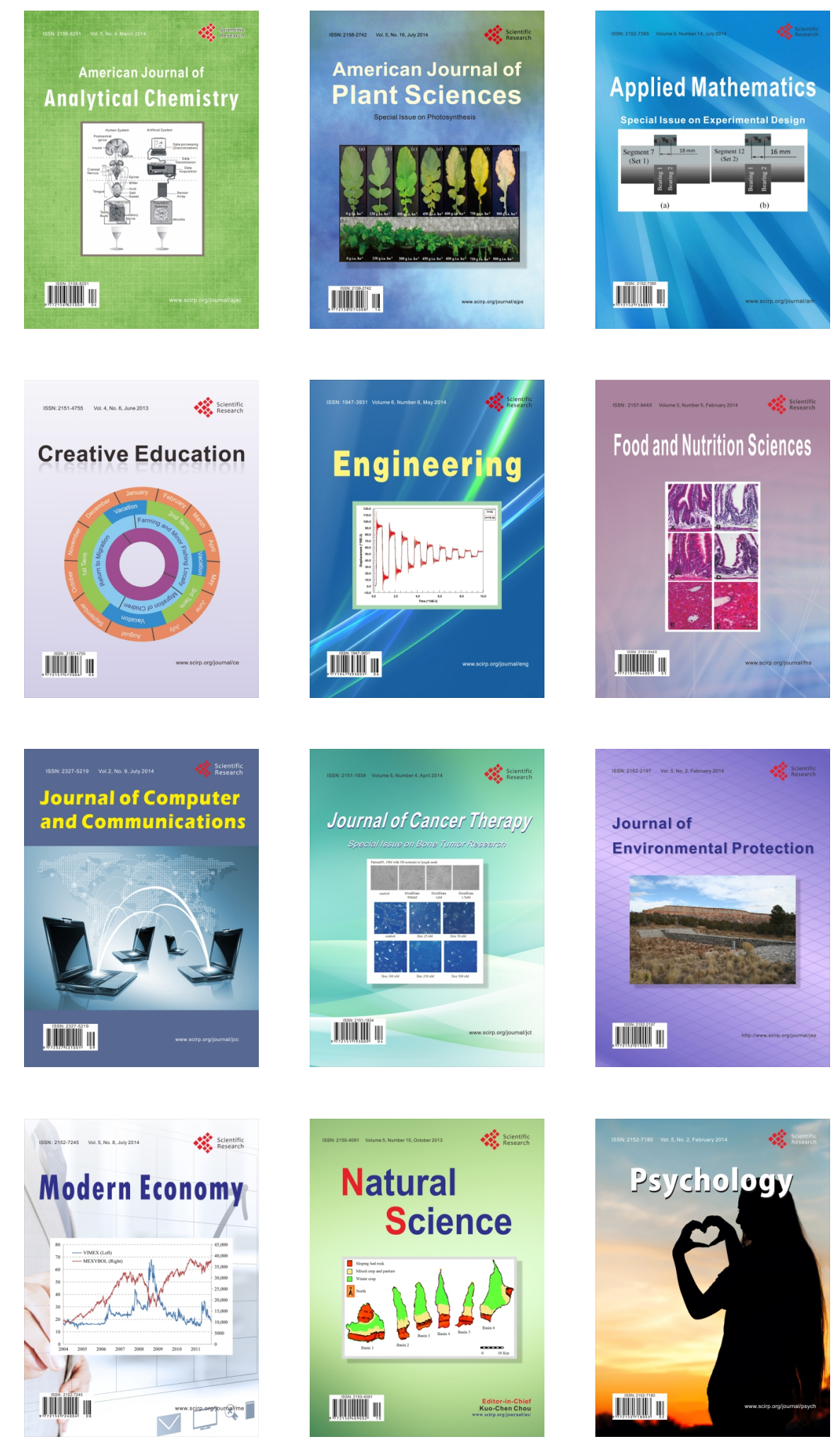